\title{
Condicional e ir no Imperfeito + Infinitivo: questões de temporalidade e de modalidade ${ }^{1}$
}

\author{
Luís Filipe Cunha \\ Centro de Linguística da Universidade do Porto / Faculdade de Letras da Universidade do \\ Porto
}

\begin{abstract}
:
In European Portuguese, both the Condicional (approximately corresponding to the English structure would + Infinitive) and the construction ir ('go') in the Imperfect + Infinitive express posteriority with respect to a given past interval. In this paper, I show that, in spite of their seemingly similar behaviour, these two forms diverge in a number of significant aspects. In particular, and taking into account the analysis of contexts such as if-clauses and some subordinate complement clauses introduced by factive and intensional verbs, I will argue that, while the Condicional is mainly used to provide modal information, even losing its basic temporal value, the structure $i r$ ('go') in the Imperfect + Infinitive always induces a temporal relation of futurity in a past domain, irrespective of the possible modal meanings accompanying it.
\end{abstract}

Keywords: semantics, temporal relations, Condicional, ir ('go') + Infinitive, modality.

Palavras-chave: Semântica, relações temporais, Condicional, ir + Infinitivo, modalidade.

\section{Introdução}

Em termos muito gerais, diremos que, em Português Europeu, é possível constatar que as formas do Condicional - por vezes também designado como "futuro do passado" (cf. Cunha \& Cintra, 1984; Peres, 1993) - e a construção ir no Imperfeito + Infinitivo partilham propriedades semânticas comuns bastante significativas. Em particular, (i) em circunstâncias adequadas, ambas podem veicular informação temporal de posterioridade em relação a um dado Ponto de Perspetiva Temporal ${ }^{2}$ passado (cf. (1)-(2)) e (ii) propiciam facilmente o surgimento de interpretações de natureza modal (cf. (3)-(4)), embora, na maior parte dos casos, como procuraremos demonstrar ao longo do presente trabalho, com implicações algo distintas (cf. e.g. Oliveira \& Duarte, 2014; Cunha, 2015).

(1) O deputado socialista receberia, pouco depois, o apoio do social-democrata Rosa Pires. (CetemPúblico, par=ext126303-soc-95b-1)

\footnotetext{
${ }^{1}$ Trabalho financiado pela Fundação para a Ciência e a Tecnologia no âmbito do QREN - POPH - Tipologia 4.1. - Formação avançada, comparticipado pelo Fundo Social Europeu e por fundos nacionais do MEC.

${ }^{2}$ Para a caracterização da noção de Ponto de Perspetiva Temporal, doravante PPT, vejam-se, por exemplo, Kamp \& Rohrer (1983) ou Kamp \& Reyle (1993).
} 
(2) O deputado socialista ia receber, pouco depois, o apoio do social-democrata Rosa Pires.

(3) Em 1985, a Grundig AG e a Blaupunkt celebraram um acordo, segundo o qual a primeira receberia toda a produção de televisores da Blaupunkt, que, por sua vez, ficaria com a produção de auto-rádios Grundig. (CetemPúblico, par=ext106899-eco-92b-1)

(4) Em 1985, a Grundig AG e a Blaupunkt celebraram um acordo, segundo o qual a primeira ia receber toda a produção de televisores da Blaupunkt, que, por sua vez, ia ficar com a produção de auto-rádios Grundig. ${ }^{3}$

Os exemplos (1) e (2) ilustram a equivalência, em termos de informação temporal, que podemos observar entre o uso do Condicional e da estrutura ir no Imperfeito + Infinitivo. Na realidade, em ambos os casos, temos um marcador temporal, "pouco depois", que remete para um período de tempo posterior a um dado intervalo passado (aqui não especificado), que, por sua vez, se constitui como o PPT relevante para a frase em questão. A situação descrita, i.e., "O deputado socialista receber o apoio do social-democrata Rosa Pires", realiza-se no período de tempo especificado pelo adverbial, ou seja, é posterior ao PPT selecionado, independentemente de ocorrer o Condicional ou ir no Imperfeito + Infinitivo.

Uma equivalência semelhante parece emergir nas frases de (3) e (4): nestes exemplos, as orações contendo o Condicional ou a estrutura ir no Imperfeito + Infinitivo dão conta de proposições que descrevem os termos do acordo celebrado entre a Grundig AG e a Blaupunkt em 1985. Em qualquer das ocorrências, não dispomos de informação suficiente para saber se as eventualidades em causa se realizaram ou não no mundo de referência, o que nos leva a considerar que estamos perante um caso de interpretação modalizada - provavelmente de cariz deôntico - das formas verbais em questão.

Significarão as equivalências que acabámos de constatar que existe uma identidade semântica perfeita entre o Condicional e a construção ir no Imperfeito + Infinitivo? A resposta a esta questão parece ser negativa, se tivermos em conta contrastes como o apresentado em (5) e (6):

\footnotetext{
${ }^{3}$ Tal como indicado no texto, os exemplos (1) e (3) foram retirados do corpus CetemPúblico, disponível em www.linguateca.pt; os exemplos (2) e (4) foram manipulados por nós com o objetivo de manter toda a estrutura frásica inalterada, comutando apenas a forma verbal relevante, no sentido de evitar interferências indesejáveis na comparação que aqui nos ocupa. Adotaremos este procedimento ao longo do presente trabalho. 
(5) Quanto à arma utilizada, uma pistola de calibre 6,35mm, de origem desconhecida, já estaria na posse de Vítor Santos algumas horas antes da morte. (CetemPúblico, par=ext66015-soc-97a-2)

(6) * Quanto à arma utilizada, uma pistola de calibre 6,35mm, de origem desconhecida, já ia estar na posse de Vítor Santos algumas horas antes da morte.

Dadas as similaridades evidentes observadas entre o Condicional e a construção ir no Imperfeito + Infinitivo, o que justificará a agramaticalidade de (6) face à plena aceitabilidade de (5)? Ou, em termos mais gerais, como explicar o facto de, em certos contextos, como os representados em (1)-(4), o Condicional e a estrutura ir no Imperfeito + Infinitivo ostentarem propriedades semânticas semelhantes e noutros, como (5) e (6), se comportarem de forma claramente distinta?

No sentido de obtermos uma resposta satisfatória para as questões que acabámos de formular, propomo-nos proceder, ao longo do presente trabalho, a uma comparação tão sistemática quanto possível entre as interpretações exibidas pelo Condicional e por ir no Imperfeito + Infinitivo em diferentes contextos de ocorrência. Começaremos por uma breve abordagem às suas leituras eminentemente temporais, passando, em seguida, à análise de alguns contextos em que são claramente favorecidas interpretações de índole modal, nomeadamente as orações condicionais e certas completivas de verbo, conferindo especial atenção à distinção entre verbos introdutores de cariz factivo, como descobrir ou constatar vs verbos introdutores que promovem leituras essencialmente intensionais, do género de imaginar ou de acreditar.

\section{A interpretação temporal do Condicional e de ir no Imperfeito + Infinitivo}

Como já referimos atrás, tanto o Condicional quanto a estrutura ir no Imperfeito + Infinitivo veiculam informação de posterioridade relativamente a um domínio temporal do passado. Nessa medida, localizam tipicamente as situações com que se combinam num período de tempo que se segue a um determinado Ponto de Perspetiva Temporal passado préestabelecido (cf. Kamp \& Reyle, 1993), ou, seguindo a terminologia proposta por Declerck (1991; 2006), constituem-se como tempos que marcam posterioridade na esfera temporal do passado. Considerem-se os seguintes exemplos ilustrativos: 
(7) Foi nesta dependência que, apesar da degradação do edifício, os vereadores se reuniram, nesse mesmo ano, como era costume, aliás, no dia da procissão do Corpo de Deus, para ali envergarem as respetivas fardas e insígnias com que acompanhariam a procissão que saía da Sé. E ali voltariam, finda a cerimónia, para se desfardarem. (Germano Silva, "A Praça de S. João", Jornal de Notícias, 29 de maio de 2016. Recolhido em http://cadernosdalibania.blogspot.pt/2016/05/a-praca-de-s-joao.html)

(8) Foi nesta dependência que, apesar da degradação do edifício, os vereadores se reuniram, nesse mesmo ano, como era costume, aliás, no dia da procissão do Corpo de Deus, para ali envergarem as respetivas fardas e insígnias com que iam acompanhar a procissão que saía da Sé. E ali iam voltar, finda a cerimónia, para se desfardarem.

Nos exemplos (7) e (8), a eventualidade apresentada no Pretérito Perfeito, i.e., "os vereadores reunirem-se nesta dependência" constitui-se como o PPT passado em função do qual as situações que ocorrem com o Condicional ou com ir no Imperfeito + Infinitivo vão ser localizadas. Em ambos os casos estabelece-se uma relação inequívoca de posterioridade, ou seja, "acompanhar a procissão" e "ali voltar finda a cerimónia" decorrem num período de tempo futuro relativamente a "reunir-se", o PPT selecionado.

Tomando em consideração que, no que respeita à sua interpretação de natureza temporal, tanto o Condicional quanto ir no Imperfeito + Infinitivo requerem a presença obrigatória de um intervalo de tempo adicional, disjunto do momento da enunciação - no caso em apreço, pertencente ao domínio do passado -, que lhes irá servir como PPT para que possam ser devidamente interpretados, diremos que estamos face a tempos relativos ou anafóricos.

O PPT relevante é tipicamente disponibilizado ou por expressões e adverbiais temporais ou, mais frequentemente, por outras eventualidades representadas no discurso, nomeadamente em frases ordenadas em sequências narrativas (cf. (7)-(8)) ou no contexto de verbos introdutores de orações completivas, como ilustrado em (9) e (10):

(9) Nestas circunstâncias, a BP, contactada pelo Público, confirmou que manteria a política de preços na sua única «bomba» de Braga, isto é, continuaria a comercializar gasolinas e gasóleo mais baratos dois escudos por litro do que a concorrência. (CetemPúblico, par=ext309158-eco-95b-1) 
(10) Nestas circunstâncias, a BP, contactada pelo Público, confirmou que ia manter a política de preços na sua única «bomba» de Braga, isto é, ia continuar a comercializar gasolinas e gasóleo mais baratos dois escudos por litro do que a concorrência.

Uma consequência previsível da sua estreita dependência em relação a um dado PPT passado prende-se com o facto de que nem o Condicional nem a construção ir no Imperfeito + Infinitivo, na sua interpretação temporal, se ligam diretamente ao momento da enunciação. Na realidade, e tal como já foi observado, por exemplo, por Martínez-Atienza (2012) ou por Vatrican (2014), as situações que comparecem com o Condicional ou com ir no Imperfeito + Infinitivo tanto podem estabelecer uma relação de precedência, quanto de sobreposição ou de sucessividade com o "agora" da enunciação (desde que, naturalmente, seja preservado o seu significado básico de posterioridade em relação a um intervalo passado), como, de resto, a plena compatibilidade com os vários adverbiais temporais nos exemplos que se seguem nos confirma:

(11) Numa outra conferência de imprensa, Chakhrai anunciou que o Presidente apresentaria ontem / hoje / amanhã o seu projecto de Constituição aos dirigentes das repúblicas e regiões, contornando assim, num primeiro tempo, a oposição parlamentar. (adaptado de CetemPúblico, par=ext1519602-pol-93a-2)

(12) Numa outra conferência de imprensa, Chakhrai anunciou que o Presidente ia apresentar ontem / hoje / amanhã o seu projecto de Constituição aos dirigentes das repúblicas e regiões, contornando assim, num primeiro tempo, a oposição parlamentar.

Tomando em linha de conta que as situações representadas pelo Condicional ou por ir no Imperfeito + Infinitivo em exemplos como os apresentados em (11) e (12) são temporalmente dependentes do intervalo disponibilizado pela eventualidade associada ao verbo matriz no Pretérito Perfeito, que se constitui como o PPT relevante com o qual estabelecem uma relação de posterioridade, nada parece impedir que possam ocorrer antes, durante ou depois do momento da enunciação, tal como a compatiblidade com os adverbiais "ontem", "hoje" e "amanhã" nos sugere, tanto mais que, não se verificando qualquer conexão direta com o "agora" da enunciação, esta acaba por ser, por assim dizer, indeterminada. 
Como ficou claro a partir da comparação dos exemplos que foram apresentados ao longo da presente secção deste trabalho, as propriedades temporais do Condicional e de ir no Imperfeito + Infinitivo são, grosso modo, coincidentes. Na realidade, ambas as formas estabelecem uma relação temporal de posterioridade face a um determinado PPT, que, por sua vez, é anterior ao momento da enunciação, ou seja, exprimem futuridade em relação a um domínio passado.

Um tal facto poderia conduzir à conclusão de que a sua caracterização semântica seria, essencialmente, a mesma. No entanto, como veremos em seguida, existem diversos contextos linguísticos em que estas duas formas divergem significativamente, o que nos forçará a pôr em causa o princípio da identidade entre Condicional e a estrutura ir no Imperfeito + Infinitivo e nos levará a procurar uma descrição adequada que permita dar conta das diferenças observadas, preservando, simultaneamente, os pontos de contacto que se podem identificar entre os tempos verbais em análise.

\section{Valores modais do Condicional e de ir no Imperfeito + Infinitivo}

O facto de o Condicional e de a estrutura ir no Imperfeito + Infinitivo se comportarem, tipicamente, como futuros do passado, localizando as situações com que se combinam num intervalo posterior ao respetivo PPT, sem qualquer dependência direta em relação ao momento da fala, conduz, em certa medida, a uma consequência de inegável relevância: tal como sucede com qualquer outro tempo que exprime futuridade, também nestes casos a realização da eventualidade no mundo de referência não se encontra de todo assegurada, tal só se verificando se estiver presente informação explícita de que a situação em causa teve lugar antes do momento da enunciação.

Nesse sentido, estes tempos revelam-se particularmente adequados para a expressão de significados de natureza modal, em particular porque se torna necessário ter em conta a existência de diversas possibilidades para o curso futuro das eventualidades envolvidas, tal como previsto por Dowty (1979) na proposta que desenvolveu acerca dos designados futuros ramificantes (inertia futures).

Não surpreende, pois, que, para além do seu significado puramente temporal, tanto o Condicional quanto ir no Imperfeito + Infinitivo se encontrem associados a um conjunto de leituras modais de índole muito diversa. Como veremos, porém, verificam-se diferenças significativas quanto aos valores modais que cada um destes tempos poderá assumir, o que 
indicia que, em termos semânticos, eles não podem ser considerados elementos inteiramente idênticos.

Nas próximas subsecções deste trabalho procuraremos analisar alguns dos contextos que facilitam a emergência de leituras de índole modal em que comparecem o Condicional e a estrutura ir no Imperfeito + Infinitivo, prestando especial atenção às semelhanças e diferenças que exibem. Assim, em 3.1, debruçar-nos-emos brevemente sobre o que sucede no âmbito de orações condicionais; em 3.2, investigaremos as completivas de verbo, conferindo especial destaque à distinção entre verbos introdutores de cariz factivo como descobrir ou constatar em contraposição com verbos introdutores que favorecem interpretações essencialmente intensionais como imaginar ou acreditar, e, por fim, em 3.3, faremos referência a outros usos modais que se afiguram relevantes.

\subsection{Orações condicionais}

Um dos contextos em que o Condicional é mais frequentemente associado à expressão de valores modais é, sem dúvida, o das orações condicionais (cf. e.g. Vatrican, 2014). Nos casos mais representativos, esta forma verbal constitui-se como o núcleo de uma proposição hipotética que ocorre como apódose, combinando-se com prótases que normalmente surgem com o Imperfeito do Conjuntivo, tal como ilustrado no exemplo que se segue: ${ }^{4}$

(13) Certa vez que lhe apeteceu ovos cozidos apostou com a malta em como era capaz de comer 50 seguidos: se os comesse pagaríamos nós, de contrário pagaria ele. (CetemPúblico, par=ext265047-clt-98b-2)

Em Português Europeu, o Condicional pode ser essencialmente encontrado em condicionais de cariz potencial, como a representada em (14), ou em condicionais contrafactuais, como exemplificado em (15):

\footnotetext{
${ }^{4}$ Tendo em conta os objetivos específicos do presente trabalho e dada a grande complexidade que as estruturas condicionais envolvem e a profusão de literatura sobre o tema, não entraremos aqui na discussão acerca da sua caracterização semântica, limitando-nos a apontar os factos que consideramos mais relevantes para o estudo que estamos a desenvolver. Sobre o uso de diferentes tempos em condicionais no PE, veja-se, por exemplo, Ferreira (1996).

№ 3 - 09/ 2017 | 75-98 | https://doi.org/ 10.26334/2183-9077/rapln3ano2017a6 
(14) Se o asteróide caísse no oceano, os efeitos também seriam catastróficos. (CetemPúblico, par=ext75581-nd-91b-1)

(15) E como que a demonstrar a bondade do PS-Gaia, o autarca afiança que «autorizaria um empréstimo de cinco milhões ou de dez milhões [...] se o dr. Luís Filipe Menezes tivesse apresentado um projecto muito grande». (CetemPúblico, par=ext1439958-soc-98a-1)

Em qualquer dos casos, e tal como salientado por Vatrican (2014), o Condicional veicula modalidade, no sentido em que dá conta de uma proposição que (ainda) não se concretizou no mundo de referência, i.e., uma proposição que pode ser caracterizada como pertencendo ao domínio do não-real ou do não-factual. ${ }^{5}$

Aparentemente, e no que diz respeito às orações condicionais, a construção ir no Imperfeito + Infinitivo parece poder comparecer nos mesmos contextos em que surge o Condicional. A aceitabilidade das sequências nas substituições efetuadas nos exemplos que se seguem vai ao encontro desta observação:

(16) Certa vez que lhe apeteceu ovos cozidos apostou com a malta em como era capaz de comer 50 seguidos: se os comesse íamos pagar nós, de contrário ia pagar ele.

(17) Se o asteróide caísse no oceano, os efeitos também iam ser catastróficos.

(18) E como que a demonstrar a bondade do PS-Gaia, o autarca afiança que «(?) ia autorizar um empréstimo de cinco milhões ou de dez milhões [...] se o dr. Luís Filipe Menezes tivesse apresentado um projecto muito grande».

No entanto, importa sublinhar que uma tal equivalência não parece poder estender-se a todos os contextos relevantes. Por exemplo, Oliveira \& Duarte (2014) sugerem que, nas orações condicionais do PE, o recurso à forma ir no Imperfeito + Infinitivo se revela impossível quando

\footnotetext{
${ }^{5}$ Embora os usos potenciais e contrafactuais partilhem certas características comuns, nomeadamente no que respeita ao facto de a proposição expressa pela matriz não ter lugar no mundo "real", é igualmente de notar que diferem substancialmente noutros aspetos. Assim, enquanto nas condicionais potenciais a situação descrita é encarada como realizável, alcançadas certas alterações relevantes das circunstâncias apresentadas, nas contrafactuais as proposições são simplesmente concebidas como totalmente impossíveis no mundo de referência. Tendo em conta que, no presente trabalho, o nosso objetivo é apenas o de investigar os contextos de comparência do Condicional e da estrutura ir no Imperfeito + Infinitivo, não aprofundaremos aqui esta e outras questões relativas ao funcionamento das orações condicionais.
} 
comparecem estativos na principal. Pelo contrário, o Condicional surge, sem quaisquer problemas, em idênticas circunstâncias. Observem-se os seguintes contrastes:

(19) Se tomasse vitaminas, ele seria alto.

(20) * Se tomasse vitaminas, ele ia ser alto. ${ }^{6}$

(21) «Se Jesus viesse hoje ao mundo Ele teria uma palavra de salvação para com os toxicodependentes como teve para os leprosos, os cegos e os deserdados da fortuna» acrescentou o mentor da iniciativa [...]. (CetemPúblico, par=ext251702-soc-92a-1)

(22) ?? «Se Jesus viesse hoje ao mundo Ele ia ter uma palavra de salvação para com os toxicodependentes como teve para os leprosos, os cegos e os deserdados da fortuna» acrescentou o mentor da iniciativa $[\ldots]$.

(23) «Não seria presidente da câmara se soubesse de algum contributo de uma empresa que negociava a sua instalação.» (CetemPúblico, par=ext548230-nd-94a-2) ${ }^{7}$

(24) \# «Não ia ser presidente da câmara se soubesse de algum contributo de uma empresa que negociava a sua instalação.»

Observe-se, todavia, que as divergências, em termos de aceitabilidade, que surpreendemos neste género de exemplos parecem não radicar exclusivamente no perfil aspetual das eventualidades envolvidas, tal como proposto em Oliveira \& Duarte (2014). Na realidade, não é difícil encontrar condicionais com estativos na oração principal que, no entanto, admitem a presença de ir no Imperfeito + Infinitivo. É o que acontece, por exemplo, em frases como (17), anteriormente apresentada, ou em (26) e (27):

\footnotetext{
${ }^{6}$ Este contraste foi construído a partir da adaptação do exemplo (26) de Oliveira \& Duarte (2014).

${ }^{7}$ Este exemplo revela-se particularmente interessante na medida em que pode receber duas leituras distintas: uma primeira, em que apenas o Condicional é possível e a estrutura ir no Imperfeito + Infinitivo dá origem a anomalia semântica, aponta para o facto de que o locutor é efetivamente presidente da Câmara no mundo de referência e no momento da enunciação, recebendo a frase condicional uma interpretação de tipo contrafactual, equivalente a "Eu não estaria a ocupar neste momento o cargo de presidente da Câmara se soubesse...". Uma segunda leitura, em que tanto o Condicional como, no entender de alguns falantes, a construção ir no Imperfeito + Infinitivo são perfeitamente aceitáveis e praticamente equivalentes em termos semânticos, será aquela em que o locutor perspetiva a presidência da Câmara como uma possibilidade futura (interpretação hipotética), correspondendo a uma paráfrase do género de "Eu não me candidataria a ser presidente da Câmara se soubesse...". 
(25) Se os ex-comunistas aceitassem participar no Executivo, a coligação governamental teria uma maioria muito confortável. (CetemPúblico, par=ext202752-pol-92a-2)

(26) Se os ex-comunistas aceitassem participar no Executivo, a coligação governamental ia ter uma maioria muito confortável.

(27) Se ganhasse o euromilhões, o João seria / ia ser o homem mais rico da cidade. ${ }^{8}$

Inversamente, algumas predicações eventivas que ocorrem na oração principal de condicionais podem, por vezes, ocasionar anomalia semântica quando combinadas com ir no Imperfeito + Infinitivo, desde que, na subordinada, compareça uma eventualidade de cariz estativo, contrastando, assim, mais uma vez, com o Condicional, que se revela perfeitamente aceitável em idênticos contextos. Os pares de frases que se seguem ilustram o que acabámos de referir:

(28) Se fosse alto, o João chegaria ao cimo do armário

\footnotetext{
${ }^{8}$ Um revisor anónimo deste trabalho assinala uma diferença, ainda que ténue, entre o Condicional e a estrutura ir no Imperfeito + Infinitivo em exemplos como estes, sugerindo que o "ponto de vista" dos participantes desempenharia um papel relevante na sua interpretação final. Assim, as construções que integram ir no Imperfeito + Infinitivo indicariam que a possibilidade em causa (a de a coligação governamental vir a ter uma maioria muito confortável, em (26), e a de o João vir a ser o homem mais rico da cidade, em (27)) existiria na mente do agente relevante (os ex-comunistas em (26) e o João em (27)), mas não necessariamente quando é usada a forma do Condicional. Por outras palavras, com o Condicional descrever-se-ia o ponto de vista do enunciador, enquanto a estrutura $i r$ + infinitivo remeteria para o ponto de vista de um qualquer outro participante na situação. No sentido de sustentar uma tal posição, apresentam-se dados como os que se seguem:
}

(i) Os primeiros colonos instalaram-se no sopé da montanha em fevereiro. Quatro meses mais tarde, o vulcão \{? ia entrar / entraria $\}$ em erupção / uma enxurrada inesperada $\{$ ? ia destruir / destruiria $\}$ a povoação.

Não é para mim, neste momento, muito claro qual o papel desempenhado pelo "ponto de vista" dos diferentes participantes na situação no que diz respeito ao licenciamento do Condicional ou da construção ir no Imperfeito + Infinitivo, tanto mais que uma alteração na ordem de constituintes na frase apresentada como argumento para a diferenciação em causa parece ser suficiente para tornar a forma ir no Imperfeito + Infinitivo perfeitamente aceitável, tal como ilustrado em (ii). Dado que uma discussão aprofundada destes fatores requer a comparação e a análise sistemática de um número muito significativo de exemplos, deixarei a sua investigação para trabalhos futuros.

(ii) Os primeiros colonos instalaram-se no sopé da montanha em fevereiro. O vulcão \{ia entrar / entraria $\}$ em erupção / uma enxurrada inesperada \{ia destruir / destruiria $\}$ a povoação quatro meses mais tarde. 
(29) \# Se fosse alto, o João ia chegar ao cimo do armário.

(30) Se fosse portuguesa, a Conchita cantaria o fado.

(31) \# Se fosse portuguesa, a Conchita ia cantar o fado.

Dado que a simples distinção entre estados e eventos não parece, por si só, dar conta dos contrastes que acabámos de apresentar, coloca-se a questão de saber em que circunstâncias é que ir no Imperfeito + Infinitivo pode ou não comparecer nas frases condicionais.

Colocaremos aqui a hipótese de que serão fatores de natureza essencialmente temporal que estão na base das discrepâncias observadas. Assim, embora a realização no mundo de referência da situação descrita na principal não esteja assegurada em nenhum dos casos analisados, ir no Imperfeito + Infinitivo imporia adicionalmente uma restrição de ordenação temporal entre as eventualidades descritas que o Condicional não exigiria.

Por outras palavras, o Condicional, ao exprimir valores modais, pode "desligar-se" por completo da informação temporal que lhe é comummente associada, deixando a relação de posterioridade no passado de se constituir como um traço definidor desta forma verbal; pelo contrário, ir no Imperfeito + Infinitivo, embora perfeitamente apto a receber leituras de índole modal, só parece poder ser licenciado se estas forem compatíveis com o seu perfil temporal básico, i.e., com a manutenção de algum tipo de relação de futuridade no passado.

Assim, a título de exemplo, numa frase como (27), em que a proposição presente na subordinada - "o João ganhar o euromilhões" - precede necessariamente a descrita na principal - "ser o homem mais rico da cidade" -, e independentemente do seu valor de verdade no mundo de referência, tanto o Condicional quanto a configuração ir no Imperfeito + Infinitivo são perfeitamente aceitáveis.

Pelo contrário, em frases em que a prospetividade da principal em relação à subordinada não se verifica, como em (30)-(31), em que "A Conchita ser portuguesa" e "a Conchita cantar o fado" estabelecem preferencialmente uma relação de sobreposição temporal (mais uma vez, independentemente do seu valor de verdade no mundo real), apenas o Condicional parece ser viabilizado, ao passo que a construção ir no Imperfeito + Infinitivo dá origem a uma sequência anómala.

Ora, tendo em consideração que são tipicamente os estados, e não os eventos, que favorecem uma relação temporal de sobreposição ou de inclusão, é de esperar que a comparência 
de ir no Imperfeito + Infinitivo esteja sujeita a maiores restrições neste tipo de contexto, tal como observado em Oliveira \& Duarte (2014). No entanto, e como (17), (26) e (27) parecem indicar, logo que os estativos participam em condicionais em que a sequencialidade das situações se torna evidente, ir no Imperfeito + Infinitivo passa a ser uma opção completamente aceitável.

Em suma, e embora estejamos conscientes de que muita investigação ficou ainda por realizar no que respeita às condições que regem a comparência do Condicional e de ir no Imperfeito + Infinitivo no contexto das orações condicionais, podemos, desde já, avançar com a seguinte hipótese de análise: se é certo que tanto o Condicional quanto ir no Imperfeito + Infinitivo estão aptos a expressar valores modais, existe uma importante diferença no que toca ao seu comportamento linguístico. Enquanto o Condicional, nas suas interpretações modais, parece não ser sempre sensível às conexões temporais que se estabelecem entre as proposições, ir no Imperfeito + Infinitivo requer a manutenção do seu perfil temporal básico, i.e., exige, para o seu licenciamento, a presença de uma relação de prospetividade no passado. ${ }^{9}$

Vejamos, em seguida, se a distinção que acabámos de propor se mantém noutros contextos linguísticos.

\subsection{Completivas de verbo}

Um outro contexto linguístico em que as semelhanças e as divergências entre o Condicional e a estrutura ir no Imperfeito + Infinitivo são claramente percetíveis é, sem dúvida, o das completivas de verbo.

Nos casos em que uma interpretação temporal de posterioridade é explicitamente favorecida, como acontece em frases contemplando verbos introdutores que, de alguma forma, forçam uma leitura futurativa da situação expressa na subordinada - considerem-se, a título de exemplo, verbos do género de prometer ou de decidir, que lexicalmente determinam a posterioridade das eventualidades representadas na frase encaixada -, não parecem existir diferenças interpretativas de monta entre o Condicional e a construção ir no Imperfeito + Infinitivo, tal como a equivalência entre os exemplos que se seguem nos confirma:

\footnotetext{
${ }^{9}$ Neste trabalho limitamos a nossa análise das orações condicionais às relações temporais que se podem observar com as formas simples do Condicional e de ir no Imperfeito + Infinitivo, deixando os tempos compostos correspondentes, que parecem ostentar um comportamento algo divergente, para estudos posteriores. 
(32) Em Outubro, o Comissariado concluiu que não sobrevivia com 115 mil contos e a Sec prometeu que concederia mais 150 mil contos em três prestações. (CetemPúblico, par=ext527428-clt-92b-2)

(33) Em Outubro, o Comissariado concluiu que não sobrevivia com 115 mil contos e a Sec prometeu que ia conceder mais 150 mil contos em três prestações.

(34) No entanto, o autarca não desarmou quanto à intenção de concretizar o projecto e prometeu que manteria as conversações com a Junta de Freguesia e os munícipes por forma a resolver o problema.

(35) No entanto, o autarca não desarmou quanto à intenção de concretizar o projecto e prometeu que ia manter as conversações com a Junta de Freguesia e os munícipes por forma a resolver o problema. (CetemPúblico, par=ext165941-soc-97a-1)

No entanto, somos, por vezes, confrontados com outros tipos de completivas em que as divergências entre o Condicional e a estrutura ir no Imperfeito + Infinitivo se manifestam de forma bastante evidente.

Verbos introdutores de cariz factivo, i.e., verbos que tipicamente implicam a verdade da situação da frase encaixada no mundo de referência, de que são exemplo constatar ou descobrir, são, por natureza, menos afeitos à expressão da modalidade.

$\mathrm{Na}$ realidade, ao favorecerem interpretações em que as proposições no seu escopo são verdadeiras em $w 0$, o mundo "real", estes verbos apenas admitem leituras futurativas em que se verifique um alto grau de certeza relativamente à efetiva concretização das eventualidades em causa.

Tendo em conta que o Condicional, no contexto de orações completivas, exprime de preferência informação de natureza modal, não surpreende que, quando combinado com verbos factivos do género de constatar ou descobrir, dê origem a um certo grau de anomalia semântica, como ilustrado nos exemplos seguintes: 
(36) ?? Os meteorologistas constataram que choveria.

(37) ?? O polícia descobriu que os rapazes partiriam a montra da ourivesaria. ${ }^{10}$

Contrariamente ao que sucede com o Condicional, a estrutura ir no Imperfeito + Infinitivo parece poder comparecer, sem problemas, sob o escopo de verbos factivos do tipo de constatar ou descobrir, veiculando uma leitura temporal de posterioridade no passado. Com efeito, se substituirmos as formas de Condicional pela construção ir no Imperfeito + Infinitivo, a aceitabilidade das frases (36) e (37) melhora de modo muito significativo (cf. (38)-(39)):

Os meteorologistas constataram que ia chover.

O polícia descobriu que os rapazes iam partir a montra da ourivesaria.

Se colocarmos a hipótese de que a construção ir no Imperfeito + Infinitivo se caracteriza, em primeiro lugar, por veicular informação de índole temporal, contrastando com o Condicional, que, por seu lado, seria preferencialmente utilizado em contextos modais, obteremos pistas interessantes com vista a uma explicação adequada para os factos que acabámos de observar.

Assim, ir no Imperfeito + Infinitivo, ao proceder unicamente à localização da situação relevante num intervalo de tempo posterior ao PPT fornecido pelo verbo matriz, não interferiria, à partida, com as condições de verdade da proposição em causa, sendo, por conseguinte, compatível com uma interpretação factiva da mesma. Se, por outro lado, considerarmos que o Condicional, no contexto de completivas de verbo, acarreta alterações, a nível modal, das predicações com que coocorre, então, previsivelmente, não se poderia constituir como a forma verbal mais adequada para comparecer em estruturas envolvendo verbos introdutores de cariz

\footnotetext{
${ }^{10}$ Curiosamente, o Condicional pode surgir com verbos como constatar e decidir se integrar uma oração condicional (cf. (i)-(ii)). No entanto, nestes casos, o licenciamento da forma verbal em causa parece estar exclusivamente dependente da construção condicional em si e não do verbo introdutor da completiva. Por razões que se prendem com os limites impostos ao presente artigo, deixaremos uma investigação mais aprofundada desta questão para próximos trabalhos.
}

(iii) Os meteorologistas constataram que choveria se a superfície frontal se aproximasse.

(iv) (ii) $\mathrm{O}$ polícia descobriu que os rapazes partiriam a montra da ourivesaria se encontrassem pedras suficientes para o efeito. 
factivo, na medida em que, tendencialmente, acabaria por ter algum impacto no valor de verdade das eventualidades expressas.

Considerem-se, finalmente, alguns verbos introdutores de completivas, do género de imaginar ou de acreditar, que abrem caminho a contextos intensionais, ou seja, que favorecem interpretações não verídicas das proposições com que se combinam.

Dado que, contrariamente ao que sucede com os verbos factivos que acabámos de discutir, no presente caso a realização das proposições no mundo de referência não é obrigatória, tanto o Condicional quanto ir no Imperfeito + Infinitivo parecem poder exprimir futuridade no passado sem se encontrarem sujeitos a grandes condicionalismos, tal como as equivalências entre os exemplos que se seguem nos revelam:

(40) Costumo dizer que, tal como Samora Machel -- digam o que quiserem, mas Samora Machel foi tudo menos racista; ele acreditou que faria em Moçambique uma sociedade multirracial --, eu sou daltónico. (CetemPúblico, par=ext1506402-nd-93b-2)

(41) Costumo dizer que, tal como Samora Machel -- digam o que quiserem, mas Samora Machel foi tudo menos racista; ele acreditou que ia fazer em Moçambique uma sociedade multirracial --, eu sou daltónico.

(42) O polícia imaginou que solucionaria o caso dentro de uma semana. ${ }^{11}$

(43) O polícia imaginou que ia solucionar o caso dentro de uma semana.

Nas frases apresentadas acima, tanto o Condicional quanto ir no Imperfeito + Infinitivo localizam as eventualidades a que se aplicam num intervalo de tempo posterior ao PPT fornecido pelo verbo matriz, podendo a situação vir ou não a realizar-se em $w 0$. Por outras palavras, este tipo de exemplos combina propriedades temporais e modais, o que significa, em última instância, que ambas as formas verbais serão admissíveis no contexto em apreço.

No entanto, existem casos em que a equivalência semântica entre o Condicional e a construção ir no Imperfeito + Infinitivo no contexto de verbos introdutores de cariz intensional deixa de se verificar. Observem-se os seguintes exemplos

\footnotetext{
${ }^{11}$ Sublinhe-se, de passagem, que, mesmo nos casos em que o Condicional exprime futuridade no passado no contexto de verbos intensionais, é frequente surpreender marcas evidentes de modalidade associadas, em particular relacionadas com volição, desejo, intenção ou predição. 
(44) Os jornalistas acreditaram que o ministro estaria no seu gabinete (nesse momento / daí a dois dias).

(45) Os jornalistas acreditaram que o ministro ia estar no seu gabinete (* nesse momento / daí a dois dias).

(46) O Pedro imaginou que o João teria uma imensa fortuna (quando o conheceu / daí a dois anos).

(47) O Pedro imaginou que o João ia ter uma imensa fortuna (* quando o conheceu / daí a dois anos). ${ }^{12}$

Para além da interpretação futurativa que já foi referida anteriormente, frases como (44) e (46) podem receber igualmente uma leitura em que a situação descrita na subordinada é encarada como uma possibilidade não confirmada ou como uma hipótese a considerar: trata-se do designado Condicional de probabilidade (cf. Martínez-Atienza, 2012) ou Condicional de conjetura (cf. Vatrican, 2014).

Neste tipo de interpretação, a situação expressa na subordinada, embora concebida apenas como possível no mundo de referência, estabelece tipicamente uma relação de sobreposição temporal com o PPT fornecido pela eventualidade representada na frase matriz, como a compatibilidade com adverbiais do género de "nesse momento" ou com orações temporais como "quando o conheceu" parece confirmar. Isto significa, em última instância, que o Condicional pode perder por completo a sua informação temporal de base, dedicando-se exclusivamente à manifestação de valores modais.

Se assumirmos, pelo contrário, que a construção ir no Imperfeito + Infinitivo revela, como uma das suas propriedades semânticas fundamentais, a obrigatoriedade da manutenção de uma relação de posterioridade no passado, não surpreenderá que desencadeie anomalia semântica no contexto sob análise, já que, como referimos atrás, este favorece uma relação de sobreposição temporal entre as situações envolvidas. Por outras palavras, dado que a expressão da conjetura ou da possibilidade no contexto de verbos introdutores de completivas não implica

\footnotetext{
12 Sublinhe-se que, para a discussão destes exemplos, apenas nos interessa a interpretação em que "quando o conheceu" localiza a situação representada na subordinada, sendo aqui irrelevante a leitura em que a oração temporal se associa à frase matriz.
} 
qualquer tipo de relação de futuridade, a construção ir no Imperfeito + Infinitivo é simplesmente considerada inadequada.

Em suma, podemos afirmar que as completivas de verbo nos fornecem indicadores muito interessantes sobre as similaridades e as diferenças que se observam entre o Condicional e a estrutura ir no Imperfeito + Infinitivo, mostrando, mais uma vez, que, embora ambas se revelem capazes de exprimir temporalidade e modalidade, ir no Imperfeito + Infinitivo parece revelar um maior número de restrições quanto aos seus contextos de ocorrência em comparação com o que sucede com o Condicional, nomeadamente devido à imposição da manutenção de uma relação temporal de posterioridade.

\subsection{Outros usos modais do Condicional e de ir no Imperfeito + Infinitivo}

Não sendo, naturalmente, nosso objetivo apresentar uma caracterização exaustiva dos usos modais do Condicional e da estrutura ir no Imperfeito + Infinitivo, tendo em vista as limitações inerentes ao presente trabalho, importa, ainda assim, fazer uma breve referência a outros casos em que a diferenciação entre estas formas verbais se revela bastante evidente.

Um destes contextos, que, de resto, já foi brevemente abordado na subsecção anterior, prende-se com os designados usos potenciais ou conjeturais do Condicional. Como já referimos, o Condicional de probabilidade (cf. Martínez-Atienza, 2012) ou de conjetura (cf. Vatrican, 2014) exprime proposições cujo valor de verdade não se encontra atestado no mundo de referência, funcionando, assim, como uma espécie de operador epistémico de possibilidade, ou seja, apresenta a ocorrência da situação com que se combina como possível ou mesmo provável, mas não validada nem confirmada em $w 0$. Considerem-se os seguintes exemplos:

(48) A Praça de S. João ficaria, portanto, muito perto do edifício onde funcionava o Senado, ou seja, a Câmara Municipal, e que tinha a entrada voltada para a Rua de S. Sebastião. (Germano Silva, “A Praça de S. João”, Jornal de Notícias, 29 de maio de 2016. Recolhido em http://cadernosdalibania.blogspot.pt/2016/05/a-praca-de-s-joao.html)

(49) D. Duarte promulga, a 8 de Abril, a «Lei Mental», assim chamada porque estaria já na mente de D. João I, que em seu tempo a impusera, ainda que a não formalizasse. (CetemPúblico, par=ext706115-des-94a-2) 
Dado que, em princípio, a leitura modal de conjetura ou de possibilidade anula por completo a relação temporal de posterioridade associada ao Condicional (tanto em (48) como em (49) as situações descritas tendem a sobrepor-se ao PPT selecionado), não surpreende que a estrutura ir no Imperfeito + Infinitivo seja descartada neste tipo de interpretações, como a estranheza provocada pelos exemplos (50) e (51) nos confirma:

(50) \# A Praça de S. João ia ficar, portanto, muito perto do edifício onde funcionava o Senado, ou seja, a Câmara Municipal, e que tinha a entrada voltada para a Rua de S. Sebastião. ${ }^{13}$

(51) * D. Duarte promulga, a 8 de Abril, a «Lei Mental», assim chamada porque ia estar já na mente de D. João I, que em seu tempo a impusera, ainda que a não formalizasse.

Um outro uso do Condicional frequentemente referenciado na literatura (cf. e.g. Dendale, 2001; Abouda, 2001; Squartini, 2001, entre outros), que partilha importantes propriedades semânticas com o que acabámos de discutir, é o designado Condicional evidencial, reportivo, jornalístico ou de rumor.

Também neste caso o valor de verdade da situação no Condicional é apresentado como não confirmado no mundo de referência, i.e., o locutor não se compromete com a factualidade das eventualidades que descreve, mas, neste tipo de estruturas, atribui a outrem a responsabilidade pela veracidade da informação veiculada.

Mais uma vez, a relação temporal de posterioridade no passado que, como vimos, se encontra frequentemente associada ao Condicional parece poder ser completamente ignorada em favor do valor modal de incerteza. Observem-se os seguintes exemplos:

(52) De acordo com uma fonte próxima da família Kardashian-Jenner, Kourtney estaria grávida de Scott Disick novamente. (exemplo retirado de http://activa.sapo.pt/famosos/2016-07-08-Kourtney-Kardashian-nao-esta-nadagravida-do-quatro-filho)

\footnotetext{
${ }^{13}$ Curiosamente, uma frase como esta pode ser interpretável, mas numa leitura completamente diferente daquela que aqui nos ocupa, i.e., numa interpretação futurativa em que a Praça de S. João não tinha ainda sido construída no intervalo tomado com PPT. 
(53) Os antecedentes criminais do estudante resumir-se-iam a uma multa por excesso de velocidade. Por isso, Cho teria possibilidade de comprar armas segundo as regras estaduais. E teria um recibo comprovando a compra de uma primeira arma, de $9 \mathrm{~mm}$, a 13 de Março, e uma segunda, de $22 \mathrm{~mm}$, na semana passada. ${ }^{14}$ (exemplo extraído de https://www.publico.pt/destaque/jornal/atirador-era-um-jovem-estudante-sulcoreanosolitario-e-perturbado-211320)

Observe-se que, tanto em (52) como em (53), somos confrontados com eventualidades cuja veracidade não é assumida pelo locutor e é atribuída a uma fonte de informação externa (inclusivamente, em (52), é explicitamente indicada a entidade responsável pela produção da predicação apresentada). Por outro lado, verificamos que a compatibilidade destas frases com adverbiais temporais como "nesse momento" revela que a sobreposição temporal ao PPT relevante parece ser a interpretação preferida. O exemplo (54), manipulado com base em (52), ilustra o que acabámos de referir:

(54) De acordo com uma fonte próxima da família Kardashian-Jenner, Kourtney estaria, nesse momento, grávida de Scott Disick novamente.

Mais uma vez, e dado que a relação temporal que se estabelece neste género de exemplos não envolve tipicamente posterioridade no passado, a estrutura ir no Imperfeito + Infinitivo revela um alto grau de anomalia semântica no contexto de configurações de evidencialidade, como ilustrado em (55) e (56):

* De acordo com uma fonte próxima da família Kardashian-Jenner, Kourtney ia estar grávida de Scott Disick novamente.

(56) * Os antecedentes criminais do estudante iam resumir-se a uma multa por excesso de velocidade. Por isso, Cho ia ter possibilidade de comprar armas segundo as regras estaduais. E ia ter um recibo comprovando a compra de uma primeira arma, de $9 \mathrm{~mm}$, a 13 de Março, e uma segunda, de $22 \mathrm{~mm}$, na semana passada.

\footnotetext{
${ }^{14}$ Embora, neste exemplo particular, não se encontre explicitamente referida uma fonte externa responsável pela assunção das afirmações produzidas, ela surge no contexto mais alargado do discurso de onde retirámos a citação em causa.

№ 3 - 09/ 2017 | 75-98 | https://doi.org/ 10.26334/2183-9077/rapln3ano2017a6 
Se, pelo contrário, estiverem em causa interpretações que remetam, de uma forma explícita, para a intencionalidade (cf. (57)) ou para algum tipo de previsibilidade (cf. (58)), i.e., em que a componente temporal de posterioridade se revele proeminente, então a construção ir no Imperfeito + Infinitivo parece ser preferida, como os exemplos que se seguem ilustram: ${ }^{15}$

(57) Dundee ia jogar hoje em Telavive ao lado de Jürgen Klinsmann num particular contra Israel, mas uma lesão sofrida no sábado fê-lo renunciar à viagem. (CetemPúblico, par=ext24137-des-97a-4)

(58) O aparelho, que devia seguir para Taipei (Taiwan), ia levantar voo quando o comandante anulou a manobra por razões ainda indeterminadas. (CetemPúblico, par=ext19440-soc-95b-2)

É interessante observar que, mesmo exibindo uma inegável componente modal - em particular, no que respeita à expressão da contrafactualidade, tal como observado em Martín (2008) -, estas configurações surgem preferencialmente em combinação com a estrutura ir no Imperfeito + Infinitivo, sendo o Condicional por vezes algo problemático nos contextos em apreço (cf. (59)-(60)):

(59) ?? Dundee jogaria hoje em Telavive ao lado de Jürgen Klinsmann num particular contra Israel, mas uma lesão sofrida no sábado fê-lo renunciar à viagem.

(60) ?? O aparelho, que devia seguir para Taipei (Taiwan), levantaria voo quando o comandante anulou a manobra por razões ainda indeterminadas.

Uma hipótese de explicação para o contraste que acabámos de observar talvez radique na constatação de que este género de configurações confere especial relevância à componente temporal de posterioridade no passado e, pelo menos em contextos como os aqui representados, se comece a verificar uma utilização mais sistemática da construção ir no Imperfeito + Infinitivo para exprimir significações em que a temporalidade recebe maior visibilidade, ao passo que o Condicional estaria a especializar-se em leituras que ostentam valores puramente modais.

\footnotetext{
${ }^{15}$ Para uma discussão aprofundada do papel desempenhado pela intencionalidade e pela previsibilidade na construção ir $a$ + Infinitivo do espanhol, veja-se Martín (2008). 


\section{Conclusão}

Da comparação sistemática, ainda que não exaustiva, entre o uso do Condicional e da construção ir no Imperfeito + Infinitivo em diferentes contextos de ocorrência parece-nos razoável extrair as seguintes conclusões:

O Condicional e a construção ir no Imperfeito + Infinitivo partilham importantes propriedades semânticas. Em particular, ambos podem exprimir posterioridade em relação a um Ponto de Perspetiva Temporal passado e veicular informação de natureza modal.

No entanto, isto não significa que as duas formas em análise se revelem semanticamente idênticas. Na realidade, são vários os contextos em que apenas uma delas parece ser admissível, sendo a outra total ou parcialmente excluída.

Nesse sentido, constatámos que o licenciamento da estrutura ir no Imperfeito + Infinitivo se encontra fortemente condicionado pela presença de marcas inequívocas de temporalidade na sequência em que ocorre. Em particular, é necessário que se verifique uma relação de posterioridade no passado para que a forma em questão possa surgir sem ocasionar anomalia semântica.

O Condicional revela-se, a este respeito, bastante mais flexível, o que explica o facto de poder comparecer em frases que, de alguma maneira, manifestam sobreposição em termos temporais (vejam-se, a título de exemplo, os designados usos conjeturais, hipotéticos, reportivos e evidenciais típicos desta forma verbal). Ainda assim, o Condicional parece começar a estar sujeito a certas restrições de ocorrência em contextos em que a estrutura ir no Imperfeito + Infinitivo surge sem problemas, apontando para uma possível futura especialização na expressão de valores puramente modais. 
Importa finalmente sublinhar que a análise que aqui levámos a cabo está longe de ser exaustiva e de cobrir todos os casos relevantes. Deixaremos para trabalhos posteriores o levantamento em corpora de um número mais significativo de exemplos por forma a avaliar a validade da hipótese por nós desenvolvida e reconhecer eventuais interferências que outros fatores linguísticos poderão ter na leitura final dos tempos gramaticais em questão. ${ }^{16}$

\section{Referências}

Abouda, Lofti, (2001) "Les emplois journalistique, polémique, et atténuatif du conditionnel. Un traitement unitaire". In Patrick Dendale \& Liliane Tasmowski (Eds.), Le conditionnel en français. Metz, Université de Metz: pp. 277-294.

Cunha, Celso, \& L. F. Lindley Cintra (1984) Nova Gramática do Português Contemporâneo. Lisboa: Edições Sá da Costa.

Cunha, Luís Filipe, (2015) “Algumas considerações em torno das interpretações da construção ir + Infinitivo com Imperfeito". In Diacrítica - Revista do Centro de Estudos

\footnotetext{
${ }^{16}$ A estrutura ir no Imperfeito + Infinitivo em Português Europeu parece não se restringir aos usos temporais que aqui observámos, revelando uma grande complexidade. Agradeço a um revisor anónimo o facto de me ter chamado a atenção para exemplos como os que se seguem:
}

(i) Quando ia abrir a porta, tocou o telefone.

(ii) Chegaste mesmo quando eu ia sair.

Casos como os ilustrados em (i) e (ii) parecem configurar um terceiro valor de $i r+$ Infinitivo, que difere substancialmente tanto do seu uso essencialmente temporal, que estudámos neste artigo, quanto do seu uso eminentemente lexical, abordado, por exemplo, em Cunha (2016). A confirmar esta hipótese de análise parece estar a equivalência que se verifica, nos exemplos relevantes, entre a estrutura $i r$ + Infinitivo e a forma ir a + Infinitivo, correspondência essa totalmente impossível nos restantes contextos de ocorrência, i.e., temporal ou lexical:

(iii) Quando ia a abrir a porta, tocou o telefone.

(iv) Chegaste mesmo quando eu ia a sair.

Embora se nos afigure fundamental proceder a um estudo aprofundado deste género de ocorrências, no sentido de compreender as propriedades semânticas que subjazem à estrutura ir $(a)$ + Infinitivo nos contextos em causa, pensamos que um possível caminho de análise bastante promissor para dados como estes poderá seguir a linha proposta por Martín (2008) para a configuração equivalente do espanhol. Em particular, estaríamos perante um uso aspetual da construção $\operatorname{ir}(a)$ + Infinitivo, que exprimiria uma fase pré-preparatória da situação a que se aplica. Dada a complexidade que a prossecução de um tal objetivo envolve, deixaremos a questão em aberto para trabalhos futuros. 
Humanísticos da Universidade do Minho, Série Ciências da Linguagem (Álvaro Iriarte \& Cristina Flores (eds.)), Vol. 29, n. ${ }^{\circ}$ 1: pp. 147-170.

Cunha, Luís Filipe, (2016) “Algumas peculiaridades da construção ir + Infinitivo em Português Europeu. In Revista da Associação Portuguesa de Linguística (António Moreno, Fátima Silva \& João Veloso (orgs.)), n. ${ }^{\text {o } 1: ~ p p . ~ 233-258 . ~}$

Declerck, Renaat, (1991) Tense in English: its structure and use in discourse. Londres / Nova York, Routledge.

Declerck, Renaat (2006) The grammar of the English tense system. Berlim, Mouton de Gruyter. Dendale, Patrick, (2001) “Les problèmes linguistiques du conditionnel français”. In P. Dendale \& L. Tasmowski (Eds.), Le conditionnel en français. Metz, Université de Metz, pp. 718.

Dowty, David, (1979) Word meaning and Montague grammar. Dordrecht, Reidel Publishing Company.

Ferreira, Idalina, (1996) O Tempo nas construções condicionais. Dissertação de Mestrado, Porto, Faculdade de Letras da Universidade do Porto.

Kamp, Hans \& Uwe Reyle (1993) From discourse to logic. Introduction to model-theoretic semantics of natural language, formal logic and discourse representation theory. Dordrecht, Kluwer Academic Publishers.

Martín, Ana Bravo, (2008) La perífrasis "ir a + Infinitivo" en el sistema temporal y aspectual del Español. Dissertação de Doutoramento, Madrid, Universidad Complutense de Madrid.

Martínez-Atienza, María, (2012) "Formas verbales en contraste en italiano y en español: similitudes, diferencias y explicación”. In RAEL: Revista Electrónica de Lingüística Aplicada, Vol. 11: pp. 69-86.

Oliveira, Fátima, \& Isabel Margarida Duarte (2012) “Le conditionnel et l'imparfait en Portugais Européen”. In Faits de Langues, Vol. 40, n. ${ }^{\circ}$ 2: pp. 53-60.

Peres, João Andrade, (1993) Towards an integrated view of the expression of time in Portuguese. Cadernos de Semântica, n. ${ }^{\circ}$ 14. Lisboa, Faculdade de Letras da Universidade de Lisboa. 
Luís Filipe Cunha

Squartini, Mario, (2001) "The internal structure of evidentiality in Romance". Studies in Language, Vol. 25, n. ${ }^{\circ}$ 2: pp. 297-334.

Vatrican, Axelle, (2014) “Usos y valores modales del condicional en español”. Archivum, Vol. 64: pp. 239-273. Disponível online em: http://www.unioviedo.net/reunido/index.php/RFF/article/view/10319. 